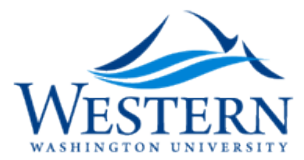

Western Washington University Western CEDAR

Fall 1998

\title{
The Changing Face of Memory and Self
}

Mark A. (Mark Anthony) Oakes

Western Washington University

Follow this and additional works at: https://cedar.wwu.edu/wwu_honors

Part of the Psychology Commons

\section{Recommended Citation}

Oakes, Mark A. (Mark Anthony), "The Changing Face of Memory and Self" (1998). WWU Honors Program Senior Projects. 252.

https://cedar.wwu.edu/wwu_honors/252

This Project is brought to you for free and open access by the WWU Graduate and Undergraduate Scholarship at Western CEDAR. It has been accepted for inclusion in WWU Honors Program Senior Projects by an authorized administrator of Western CEDAR. For more information, please contact westerncedar@wwu.edu. 
The Changing Face of Memory and Self

Mark A. Oakes

Advisor: Ira E. Hyman, Jr.

Western Washington University

* A version of this paper will appear in D. F. Bjorklund (Ed.), Research and Theory in FalseMemory Creation in Children and Adults. Hillsdale, NJ: Erlbaum. 


\section{HONORS THESIS}

In presenting this honors paper in partial requirements for a bachelor's degree at Western Washington University, I agree that the Library shall make its copies freely available for inspection. I further agree that extensive copying of this thesis is allowable only for scholarly purposes. It is understood that any publication of this thesis for commercial purposes or for financial gain shall not be allowed without my written permission.

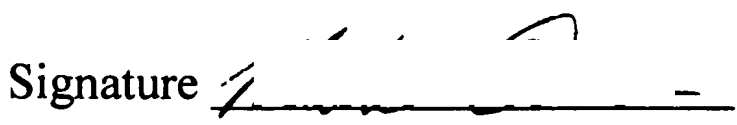

Date

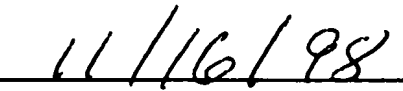


The Changing Face of Memory and Self

"To say to him 'change yourself' means to demand that everything should change, even the past." Nietzche

Who am I? At some point all of us have asked this question, looking for answers in all the obvious places: Am I a product of my environment, my genes, my family, or my friends? Part of who we are is defined by our past and our memories of our past. Using a narrative framework, people can express their diverse and complicated identities through the stories they tell. With one story, people can communicate their past, present, and future. They can describe their goals, their loves, their philosophy of life, and the moral guidelines they follow. Through this system, people can string together several categories of self-representation into a single tale or multiple stories that they share with others. In order to create these identity narratives, people must be able to access a vast network of information about their lives. Thus, memories play a vital role in the search for self. Clearly, memory and narrative do not encompass the entire definition of self. James (1890) and Neisser (1988), among many others, have argued that the self is composed of a variety of information garnered from several sources. Nonetheless, the remembered self becomes the basic fabric of self that is communicated to others and used to plan for the future.

However, there is small conundrum with this system of self-representation: memory is an unreliable foundation on which to build an identity. The retrieval of memories is dependent on current çircumstances. People can forget events, or their memories may be distorted by subsequent information. In addition, people may create entirely false memories. An individual's self concept may drive the selection of memories that are recalled, which in turn might contribute 
to the distortion of the past. Remembering is a constructive process, and while the self is constructed through memories, the construction of memories is also influenced by the self. For example, an individual may think of his- or herself as hard working. When describing the past, that person will retrieve events that fit with that description and not events that suggest laziness. Other events may be modified to fit with the hard-working description. Consequently, the types of memories that we remember and how we tell our self narratives may be altered to reflect the life themes that we have adopted. Thus the relationship between memories and self is circular: Memories define and shape the self while the self shapes the memories that are retrieved.

Imagine what happens if an individual suddenly remembers a past event that does not correspond with the self concept? Would this new piece of the puzzle change the life narrative, the identity, the self? Would the person reject the memory and deny the reality? Consider an example from a work of fiction, A Thousand Acres, by Jane Smiley (1991). Ginny, the main character is suddenly informed by her sister, Rose, that they were both sexually abused by their father. Ginny, however, does not remember any abuse and contests her sister's suggestions. Rose counters by reciting details of how she used to watch their father go into Ginny's room at night for extended periods of time, using her clock to check when he entered and left. Ginny resisted and claimed memory for shorter visits than what Rose reports. Later, however, during a visit to her father's house, Ginny laid down on the same bed she used as a child. With a flash of emotional clarity, Ginny's memory flooded back to her. "Lying here, I knew that he had been in there with me, that my father had lain with me on that bed, that I had looked at the top of his head, at his balding spot in the brown grizzled hair ... (Smiley, 1991, p. 229)." Eventually Ginny rose from the bed and left her parents' house, and she thought to herself that "a new life, yet another new life, had begun early in the day" (Smiley, 1991, p. 229). Smiley's account of Ginny's 
memory highlights the relationship between memory and identity. Her new life begins with the recovery of a memory. Therefore, the change in memory can affect an individual's entire understanding of self. A change in the past, changes the present. In Smiley's story, not only did the revelation affect Ginny's sense of self, but it also affected her relationship with her sister, Rose. Rose had always thought that the abuse, even when not part of the conversation, was an experience that they shared. Thus memories define not only the self but also the relationship of the individual to others, defining families, friends, social groups, and culture. When memory changes, people change how they conceive of themselves and their relationships with others.

Although Ginny and her memories are the fictional creation of Jane Smiley, like much fiction they represent the experiences that many real individuals have. As has been documented several times recently, people discover memories for events of which they believe they were previously unaware. This can even happen with traumatic experiences such as child abuse (Schooler, Bendikson, \& Ambadar, 1997; Williams, 1995). When people discover such experiences in their past, it affects their current understanding of their selves, alters their plans for the future, and impacts the most important relationships in their lives.

The impact of the discovered memories will be felt whether the events truly were experienced, forgotten, and only recently remembered, or whether the memories have been created via memory construction. This is important to note, for just as people can recover memories of traumatic childhood experiences, they can also create false memories. Pendergrast (1995) has told the stories of individuals who have discovered memories that were later confirmed by external sources and of individuals who recovered memories that they eventually came to believe were false. In both cases, the self-concept was dramatically affected as people began to think of themselves as abuse survivors. In both cases, relationships with family members were 
False Memory, False Self -- 6

affected. People can not easily and reliably distinguish between recovered true memories and created false memories (Hyman \& Pentland, 1996). What people know is that the memories are their memories -- thus, they act on the memories they possess, and the self and family relationships are reshaped.

In this chapter we will review the recent research on creating complete false memories, outline a theory of the processes involved in memory creation, describe some new research on those processes, and finally return for a discussion of ramifications of false memories on the self concept. If self and memory codetermine each other, how comfortable can any of us feel in our conceptualization of ourselves knowing that some of the memories that create the self may be false?

\section{Research on False Childhood Memories}

Memory researchers have studied errors in memory for a variety of materials: word lists (Roediger \& McDermott, 1995), short stories (Bartlett, 1932), songs (Hyman \& Rubin, 1990), and personal experiences (e.g., Barclay \& DeCooke, 1988, Neisser, 1982). Some of the classic research on memory errors has investigated eyewitness memory and the misinformation effect (e.g. Belli, 1989; Lindsay, 1990; Loftus, 1979; Loftus, Donders, Hoffman, \& Schooler, 1989; McCloskey \& Zaragoza, 1984; Zaragoza \& Lane, 1994). In misinformation studies people first experience an event (for example, they watch a video of a car accident), then they are given misleading post-event information or misinformation (they are told the car went past a stop sign when it actually was shown passing a yield sign), and finally they incorporate the misinformation into their recollections of the event when later tested. These studies illustrate that misinformation provided after the event occurred can alter what people remember about an event. 
The results of these misinformation studies have been applied to therapy situations where suggestions about the past are made (Lindsay \& Read, 1994; Loftus, 1993). For example, consider a person who has experienced a benign childhood (the original event). Several years later someone suggests that abuse may have occurred during childhood (the misinformation). Eventually, after several such suggestions, the person includes abuse as a part of the story of childhood. In Jane Smiley's fictional example with Ginny, Rose's suggestions of abuse could have been strong enough to mislead her sister into creating a memory-especially considering Ginny was in her childhood house, a place that cued numerous childhood memories. Thus when Ginny's growing animosity toward her father and Rose's suggestions about sexual abuse are combined within the context of true childhood memories, Ginny entered a state of mind that was very conducive to memory creation.

Such misinformation studies, however, do not provide clear evidence that a false memory for a complete event can be created through recurring suggestions. There are several differences between misinformation experiments and the creation of false childhood memories that make this comparison risky (Hyman, Husband, \& Billings, 1995). First, misinformation experiments demonstrate that aspects of an event can be created in response to misleading suggestions, but not that entire life events can be created in response to misleading suggestions. In addition, in most of the misinformation studies, the event is not related to the self nor is the self-involved in the event, while for false childhood memories the self is intimately involved. Finally, in misinformation studies the participants usually have little or no emotional involvement with the event whereas in the creation of false childhood memories the event may be very emotional. All of these differences make the creation of false childhood memories less likely that the introduction of errors to a memory. 
In response to these concerns in generalizing the misinformation effect studies, several researchers have altered the misinformation methodology and come to a general working method for studying false memories (Ceci, Huffman, Smith, \& Loftus, 1994; Ceci, Loftus, Leichtman, \& Bruck, 1994; Hyman \& Billings, 1998; Hyman, Husband, \& Billings, 1995; Hyman \& Pentland, 1996; Loftus \& Pickrell, 1995; Pezdek, Finger, \& Hodge, 1997). For the most part, researchers request from family members information about events that occurred during the participant's childhood. The participant is then asked to try to recall these true events along with a false event -- an event that the researchers are fairly sure did not happen to the participant. During a series of interviews the false event is presented as if it is also a true event that was obtained from the initial family solicitation. The participants are usually interviewed repeatedly about both the true and false events and told their memories will improve over time. The most meaningful result of this sort of study is how the participants respond to the false event -- do the participants come to believe that the event took place sometime during their childhood? Do they elaborate on the false event by importing details not contained in the original presentation of the false event? Do they contend the event is a personal memory? If this is the case, this would be evidence for the creation of an entire, self-involved, and somewhat emotional memory.

For example, Hyman et al. (1995) utilized this methodology in a study involving the childhood memories of college students. In their second experiment, the researchers obtained descriptions of true childhood events involving introductory psychology students through surveys sent to their parents. When the questionnaires were returned, the researchers asked the students to participate in a series of interviews investigating their memory for early childhood experiences. In each of three interviews (separated by one day), the students were asked to remember several true event plus one false event. For all events, the interviewer provided the students with a basic 
description (including age, event, a few actions, other people involved, and a location) and asked the students what they remembered about the event. Three different false events were used in this study. For example, one was called the punch bowl event: when you were 6 years old, you were at the wedding of a friend of the family, you were running around with some other kids when you bumped into the table the punch bowl was sitting on, and spilled on the parents of the bride. All of the false events were self-involving and would have been somewhat emotional at the time of the event, although none were traumatic events.

In general, the results of this study showed that participants recalled a majority of the true events in the first interview and remembered even more of the true events over time. There are two ways to explain the increased recall of the true events. First, by thinking about the events over a period of time, the students provided themselves with additional memory cues that led to the recollection of previously unretrieved memories. Another possibility is that the participants have created, rather than recalled, memories that match the cues provided to them in the interviews. We cannot say whether this recovery of memory for the true experience represents actual memories or the creation of memories.

Regarding the false events, no participants remembered the false event on its initial presentation, however, by the third interview $25 \%$ of the students (13 students) reported remembering the event. Six students reported memories that were very clear and included the critical information (such as turning over the punch bowl) as well as consistent elaborations (such as their parents being upset). Five of the reports were less clear; the students included little of the critical suggested information although they elaborated in a consistent fashion. Two of the students created clear images, but they were not positive about whether they were remembering or simply imagining the events that had been suggested to them. 
Although Hyman et al. used only college students in their study, other studies using varying populations (e.g. preschool children, adults, teenagers) and different false events have found similar results (Ceci, Huffman, Smith, \& Loftus, 1994; Ceci, Loftus, Leichtman, \& Bruck, 1994; Loftus \& Pickrell, 1995; Pezdek, Finger, \& Hodge, 1997). Other researchers have shown that suggestions that are not based on parent/family information have the necessary demand characteristics to create false memories (Kelley, Amodio, \& Lindsay, 1996; Lindsay, 1997; Loftus, 1997). People will create false memories of childhood experiences. These false memories can be clear, somewhat emotional, self-involved, and holistic.

Nonetheless, questions of generalizability still remain. Spilling a punch bowl at a wedding is not the same as being sexually abused. To this point, no researcher has attempted to have participants create memories of being sexually abused. For ethical reasons, it is unlikely that anyone ever will: If memories impact one's self concept and family relationships whether the memories are true or false, then experimentally inducing such memories would be atrocious. While this makes generalizing to sexual abuse memories difficult, it is not impossible. First, real world cases often provide dramatic evidence that individuals can create memories of a great variety of events. For example, two boys in Chicago recently confessed to murdering another child after being aggressively interviewed by police. Physical evidence discovered later indicated that the boys could not have committed the crime. Second, an understanding of the factors that affect memory creation and the processes involved in memory creation will allow some generalization to situations that share characteristics.

\section{Factors Contributing to False Memory Creation}

Thus research on false memories has moved to the study of factors that make memory creation more or less likely to occur. First, Hyman and his colleagues (Hyman \& Billings, 1998; 
Hyman et al., 1995) found that students' responses in the initial interview predicted who would eventually create false memories. Individuals who talked about related self-knowledge were more likely to create false memories than individuals who did not describe self-knowledge. This indicates that individuals construct false memories by combining the false suggestions with true information from their own pasts. This will make it difficult to identify a false memory because it will contain some true information. Second, Hyman and Pentland (1996) ascertained that mental imagery increases the probability of creating a false memory. Individuals who created and described images of false events were more likely to create false memories. In addition, individual differences among participants also plays a part in the creation of false childhood memories. Hyman and Billings (1998) found that false memory creation is related to the Dissociative Experiences Scale $(\underline{r}=.48)$ and the Creative Imagination Scale $(\underline{r}=.38)$. Pezdek et al. (1997) found that the plausibility of the event also plays a role. Participants are more likely to create false memories of events that match their self schemas and are thus more plausible.

These studies all relied on the basic methodology of false childhood memory research. Unfortunately, this methodology is both difficult to perform and intrusive. Thus we have been exploring a variety of different methods that allow us to investigate the processes involved in false memory creation.

\section{A Theory of False Memory Creation}

Hyman and Kleinknecht (in press) suggested three processes that are involved in the creation of false childhood memories: plausibility judgments, memory construction, and source monitoring errors of claiming the constructed narrative as a personal memory. In order for a person to create a false memory, the suggested event needs to be plausible. In other words, the event needs to be something that the person is willing to believe could have happened to them. 
For example, some participants in Hyman's studies (Hyman \& Billings, 1998; Hyman et al., 1995; Hyman \& Pentland, 1996) did not create memories of spilling a punch bowl at a wedding because they believed that they had never attended a wedding as child. They refused to accept the event as a plausible personal experience. Similarly, Pezdek et al. (1997) found that less plausible events are less likely to lead to memory creation. Plausibility is not, however, something that is automatically associated with an event. Instead, it is a judgment that people make based on various types of information.

Since plausibility is a judgment, several factors may influence whether a person sees an event as plausible. For example, the source of the suggestion will affect plausibility assessments. In the typical false memory experiment, the suggested event is presented by an experimenter and the information is based on information supposedly from the participant's parents-these are two generally reliable sources of information (although students would occasionally question their parent's accuracy). Not only will the source affect whether a person views an event as plausible, but the event itself will determine whether a person views this event as something that usually happens. For instance, most people may not consider abduction by extraterrestrials a likely event, while for others this may be an event that they consider common. Spanos, Cross, Dickson, and DuBreuil (1993) found that belief in alien visitations was the primary variable that differentiated people who claimed memories of UFO experiences from individuals who did not claim such experiences. Thus judgments about the general frequency of an event will influence plausibility judgments. In addition, suggestions that the experience is not only generally likely, but also personally likely will increase willingness to believe an event may have occurred. In this fashion, studies using false feedback (e.g., Kelley et al., 1996) are effective in part because the researchers provided reasons for the participants to believe that an experience occurred to them. 
Group membership also may affect plausibility, and thus the creation of false memories. If the new people are introduced to a group that is similar to themselves on some dimensions (common problems, experiences, world views, etc.) and if all of the other members of the group share common memories of an experience that the new members lack, then this may make the experience more plausible for the new members. This seems particularly likely if the experience is important for the group. In this case, the group's memories act as the feedback that people who share common characteristics are likely to have had a certain class of experiences. In this way, an individual without memories of abuse, who participates in a group of survivors of sexual abuse, may be receiving feedback that sexual abuse is a very probable experience for him or her. In addition, Garry, Manning, Loftus, and Sherman (1996) showed that imagining an event influences plausibility judgments. They asked participants to imagine events that they previously stated did not occur. When participants later rated the events, their ratings indicated increased acceptance that the event may have happened.

The point here is that we can manipulate people's impression of the likelihood of a suggested event having occurred. For example, consider again those students who doubted they attended a wedding and thus refused to see spilling a punch bowl as likely. In such a case, the experimenter could manipulate the participant's judgment of the event plausibility by suggesting some reasons for this belief: perhaps the student repressed memories of weddings, or perhaps the parents were embarrassed and thus never talked about it.

A person can believe that an event is likely, or even that the event occurred, but must still construct a memory; an image with a narrative. Since the time of Bartlett (1932), researchers have studied memory construction. Memory is not like videotape -- people do not simply retrieve a memory and replay the experience. Instead, people construct a memory by combining schematic 


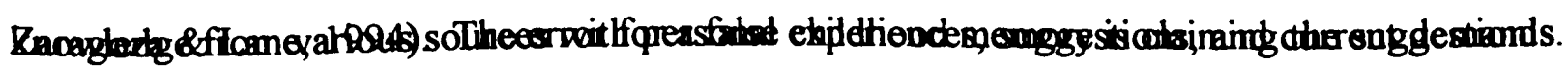
adltorionistsuatedoinagectionpersonal memory.

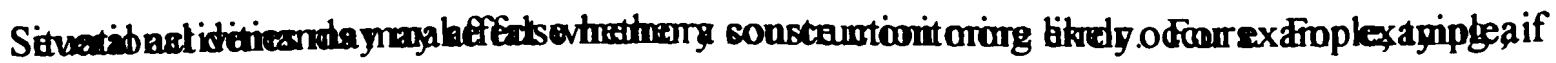

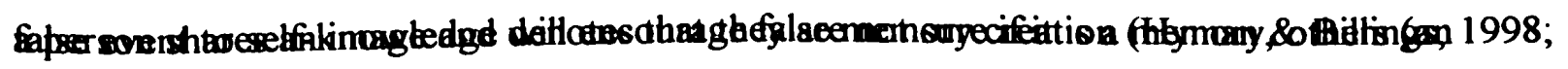

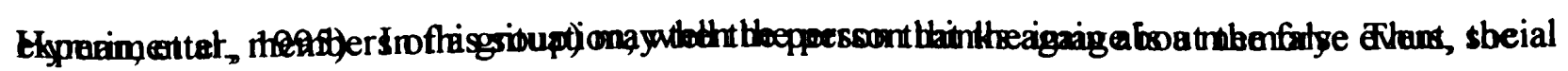

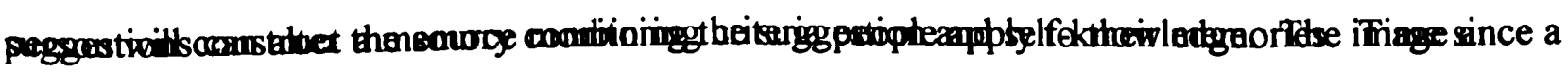

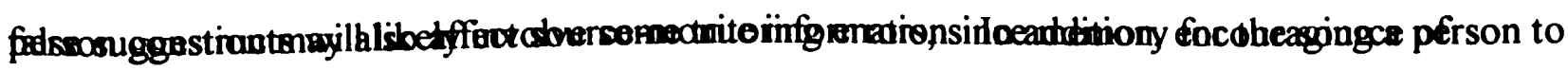

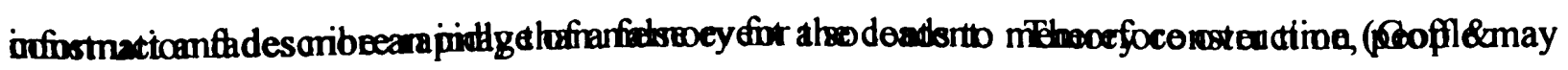

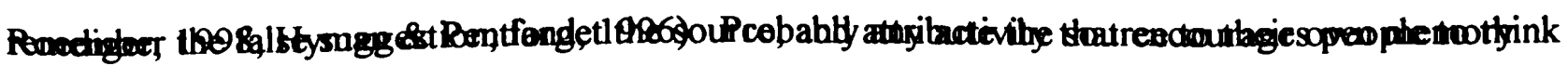

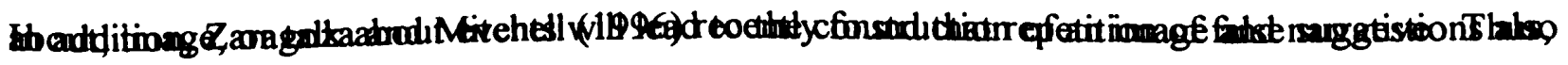

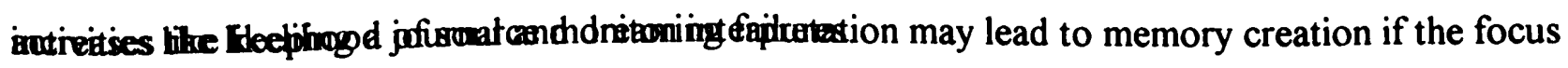

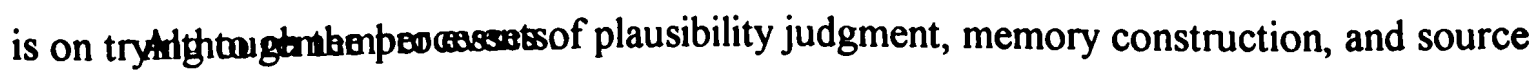
monitorfngerifor perycancbahères fashion and be dependent on the preceding step, we suspect that the processes are somewhat interactive. For example, constructing a clear image may influence one's assessment of the plausibility of an event having occurred (Garry et al., 1996). It is more correct to state that all three processes are necessary for false memory creation and that they are somewhat independent in the sense that different factors and individual differences may influence each process. Thus in our recent research, we have focused on studying plausibility judgments and source monitoring judgments separately.

\section{Plausibility Judgments}

One line of research in our lab has investigated how plausibility judgments can be manipulated. Our basic goal is to provide people reasons to believe that certain events are likely to have occurred to them. We do this by connecting childhood events that occur rarely to 
personality characteristics that we tell them they possess. Thus, our investigations of plausibility judgments are based on an extension of the Barnum effect.

In a classic investigation of the Barnum effect, individuals take a personality test and are later provided feedback supposedly based on the test. The test used does not particularly matter because the feedback is not actually based on the personality test. Instead, all participants receive identical feedback containing statements that are vague, and generally socially desirable and positive. The typical finding is that most individuals rate the resulting personality description as describing them. The effect is powerful and can be used as a teaching tool to demonstrate how people blindly accept the results of psychological tests (Forer, 1949) and of horoscopes (Glick, Gottesman, \& Jolton, 1989), and to lead into a discussion of ethics in research (Beins, 1993). In addition, the effect itself has been used to understand a variety of situations in which people accept test results as plausible and susequently diagnose themselves (c.f. Goodyear, 1990).

Our own research on plausibility judgments began as a Barnum type study (Hyman, Chesley, \& Thoelke, 1997). We went into a large introductory Psychology class and on the first day administered two personality tests: The Rotter Locus of Control Scale (1966) and the Eysenck Personality Inventory (Eysenck \& Eysenck, 1968) that assesses Neuroticism and Extroversion and includes a Lie scale. These scales were used because previous research has found that acceptance of Barnum description is related to an External Locus of Control and to higher scores on Neuroticism. The students were told that we were investigating the relationships between personality and autobiographical memory. One week later all students were provided with a packet containing their individual feedback and a follow-up questionnaire on autobiographical memory. There were 104 students who completed the study ( 58 females, 46 males, mean age $=19.05, \underline{\mathrm{SD}}=1.09$ ). The students were asked to read their personality 
description and rate how well it described them on a 7-point scale from does not describe me (1) to describe me very well (7). To this point, the experiment was a standard Barnum-effect demonstration.

After the students had rated the personality description, they were asked to respond to the autobiographical memory questionnaire: this was the extension we added to the standard Barnum methodology. All students were told that the autobiographical memory questionnaire included some events that we thought were likely to have happened to them, and other events that we thought were unlikely to have happened to them based on their personality type - thus tying together the suggested events and personality descriptions, and giving the students a reason to believe the events were personally plausible. All students were given 10 events that we told them were likely to have occurred based on their personality type and 10 that were unlikely based on their personality type. The events were counter-balanced across packets so that half the students received one set of ten likely and unlikely events and these were reversed for the remainder of the students. The students rated each event on a 7-point scale from did not happen (1) to did happen (7).

The events we used were selected based on a pilot survey to find events that are unlikely to have occurred to our population of students. In the pilot survey, 45 college students reported whether each of 70 events had happened to them before the age of 10 . We selected the events based on our own impression of low likelihood events -- events like climbing on the roof and jumping off. We then selected 20 events that had happened to fewer that $30 \%$ of our sample.

Our goals were multiple. First, we expected to replicate the Barnum effect and find that most of our students would accept the feedback as describing themselves. Second, we thought that the acceptance of feedback by the students would lead them to believe that the events we tied 
to the personality description were more likely to have happened than the events that we said were unlikely to have occurred. This would not be the creation of a false memory, but rather the first step in the process: the step of agreeing that certain events may have happened. Third, we suspected that individuals who were more accepting of the personality description would also be more likely to rate the likely events as having happened to them and that these individual differences would be tied to both locus of control and neuroticism.

The first thing to note is that most of the students rated the personality description as a good fit. The mean rating on the 7-point scale was $5.27(\underline{\mathrm{SD}}=1.13)$, and the distribution was negatively skewed so that 84 students rated the description as a five or higher and only 2 individuals gave a rating of one or two.

Although there was an overall tendency for individuals to rate the events we told them were likely as more plausible than the events we stated were unlikely, the effect was more clear for individuals who accepted the personality description. There was a significant correlation such that individuals who rated the description as a better description of themselves rated the events we told them were more likely as more plausible $(\underline{r}=.316, \underline{p}=.001)$. To put this another way, we categorized the individuals based on how completely they accepted the personality description: less acceptance for those who rated the profile a 5 or less $(\underline{n}=55)$ and higher acceptance for those with ratings of 6 or $7(\underline{n}=49)$. We then conducted a $2 \times 2$ ANOVA investigating the effects of profile acceptance and our feedback that events were likely or unlikely on the students' plausibility ratings. We found no overall effect of the profile acceptance, a marginal overall effect of our feedback $(\underline{\mathrm{F}}(1,102)=4.136, \underline{\mathrm{p}}=.045, \underline{\mathrm{MSE}}=0.512)$, and a significant interaction $(\underline{\mathrm{F}}(1$, $102)=8.268, \underline{p}=.005, \underline{M S E}=0.512$ ). As can be seen in Figure 1 , those who did not accept the profile (i.e., those with ratings of 1 to 5) were unaffected by our connecting certain events to their 
personality profile, whereas those who accepted the personality profile (i.e., those with ratings of 6 or 7 ) rated the events we told them were connected to their profile as more plausible. There was no effect for the events we told them were unlikely to have occurred, most likely because the events were selected because they were unlikely for everyone.

We also found that acceptance of the personality profile and the ratings of events we told them were likely based on the profile were correlated with some of the actual personality measures. Acceptance of the personality profile was significantly correlated with neuroticism ( $\underline{r}$ $=.323, \mathfrak{p}=.001$ ). The plausibility ratings of the events that we told them were likely based on their personality was related to the Rotter Locus of Control scale (1966), such that scores closer to the external end of the scale were related to higher plausibility ratings $(\underline{r}=.193, p=.049)$. In addition, the plausibility ratings of the likely events was also related to neuroticism $(\underline{r}=.317, \mathfrak{p}=$ $.001)$ and negatively related to the lie index $(r=-.194, p=.049)$.

These findings indicate that plausibility judgments can be manipulated. If childhood events are connected to personality characteristics, then people may begin to believe that the events happened -- whether or not they remember the events. It is important to note that the personality characterisitics need not be accurate -- it may only be necessary for individuals to believe the personality descriptions. The acceptance of events as plausible is a step in all memory error studies: All studies work to insure that the false suggestions are plausible to the participants. Further systematic exploration of factors that affect plausibility is still needed.

\section{Memory Construction and Source Monitoring}

To study source monitoring judgments, we have explored how people make 'remember' and 'know' judgment for autobiographical memories. In 1985, Tulving described a basic distinction between types of memory assessments individuals make about past experiences. 
Tulving argued, based in part on his categories of episodic memory and semantic knowledge, that there are two basic forms of awareness associated with memory: 'remember' and 'know'. When people remember, the event is re-experienced as a personal memory encompassing both selfawareness and an awareness of some of the original sensory impressions. To remember an event is to claim that the source of one's memory is a personal recollection. When a past experience comes to mind in the 'know' state of awareness, the event is recognized based on some source of knowledge without the sense of a personal memory. When applied to word lists, this is often described as familiarity absent any personal memory of hearing the word presented. For autobiographical knowledge, the other sources include external knowledge such as general selfschematic knowledge and information from parents, friends, pictures, and diaries. People can know that an event occurred to them without remembering the event.

A remember/know judgment of an autobiographical recollection is a type of source monitoring judgment. When knowledge about or an image from a past experience comes to mind, what is the source of the information? Is it a personal memory or something known from another source? This is a judgment people may regularly be faced with when recollecting childhood experiences: Is this my memory or is this based on the family story or family pictures? This is also the judgment people make if some recollection is developed in response to suggestions from other people: Is this my memory or something produced in response to the suggestions?

Thus, Hyman, Gilstrap, Decker, and Wilkinson (1998) explored how people make the remember versus know judgment in autobiographical memories. If this judgment is a source monitoring judgment, then the quality of the memory for events that people remember should differ from those associated with events they only claim to know. Johnson, Foley, Suengas, and 
Raye (1988) found that childhood events people remembered differed in many ways from childhood experiences they imagined. The events people remembered generally included much more sensory details of various sorts while the imagined events included information on the cognitive operations of constructing the image. Johnson et al. argued that the quality of the memory determined the source judgment: the more sensory detail, the more indicative these recollections are of personal memories. Thus, if the distinction between remembered and known events matched that between remembered and imagined events, this would support the claim that the remember/know judgment is a source monitoring judgment.

In Hyman et al.'s first experiment, participants first learned the definitions of remember and know. After the participants understood the definitions, they wrote a description of a childhood event (before the age of ten) for each of three categories: remember, know, and unsure if remembered or known. After they described all three events, they were asked to rate each memory on eight dimensions, including: visual detail, other sensory detail, clarity of location, clarity of time, amount of emotion, doubts about accuracy, frequency of thinking about the event, and whether the event had serious implications. These dimensions were based on the Memory Characteristics Questionnaire used by Johnson et al. (1988).

Hyman et al. found that childhood events people claimed to remember differed from events they claimed to only know on a variety of measures of memory quality, including: the amount of visual and other sensory details, the clarity of location and time knowledge, the amount of emotion, and confidence. In essence, the remembered events are clearer and contain more information. These-results, for the most part, mirrored the Johnson et al. results (1988) and therefore can be viewed as evidence for the remember/know judgment being a type of source monitoring judgment. 
One way of explaining this is that the events people know happened, but can not remember, are not a product of a personal recollection. Instead, known memories are the result of thinking about the event, hearing about the event, or imagining what took place during that experience. Thus, the source of a memory determines the quality of the memory; one has access to greater event elaboration for things one remembers.

On the other hand, this relationship could run in the opposite direction: the quality of the memory could determine the source to which someone attributes their memory. That is, if the memory is recalled with greater visual clarity, emotion, and sensory details, then one might label it as a personal memory rather than a memory that is simply known. This is congruent with Johnson's description of the source monitoring process (Johnson et al., 1988; Johnson et al., 1993). People make a source judgment based in part of the qualities of the constructed memory. If people construct a more elaborated recollection, they should be more likely to attribute the recollection to personal memory, to something they remember. Thus asking people to imagine a false childhood experiences (Hyman \& Pentland, 1996) and repeatedly imagining an event (Goff \& Roediger, 1997) increases false memories, because people create more elaborated representations of the experiences.

In keeping with this view, adding more memory qualities to a known event should result in people being more likely to claim they remember the experience. Therefore, the goal of further research exploring remember/know judgments in autobiographical memories is to determine what factors lead people to alter their source judgment for autobiographical recollection. In two additional experiments, Hyman et al. (1998) had people start with a childhood experience they claimed to know but not remember. They then asked the participants to form mental images of the experience and answer questions based on their images. Finally, individuals rated their 
recollection on a 7-point scale from know (1) to remember (7). Compared to a control group, individuals who imagined and described a known experience did rate their previously known memories further from the know end of the scale and towards the remember end, resulting in an unsure (middle) rating.

Wilkinson and Hyman (in press) used the same basic methodology to explore individual differences in source monitoring judgments. As in Hyman et al. (1998), they asked participants to start with a known childhood experience and imagine the experience in more detail. They found that individuals who showed more change in their source judgments tended to score higher on the Dissociative Experiences Scale, but were no more likely to make memory errors in remembering word lists of semantically related words (Roediger \& McDermott, 1995).

In summary, it appears that the remember/know distinction is a valuable tool for exploring source monitoring decisions for autobiographical experiences. In future research, we plan to explore how other factors influence this judgment. For example, will adding other characteristics to know events also lead people to claim to remember the event? Hyman et al. (1995) noted that making connections to self-relevant knowledge was related to the creation of false childhood memories. If people start with an event they know, focusing on the role of the self in the memory may add information unavailable from external sources (such as imagining their own thoughts and emotional responses during the event, Hyman \& Neisser, 1992) which may lead to claims of remembering the experience (Conway \& Dewhurst, 1995). In addition, this method may also be valuable for exploring how social pressures affect the source monitoring criterion that people apply to their memories. It may also be possible to use similar methodologies to convince people that they do not remember something but only know it instead. Perhaps focusing people on the 
other possible sources of their knowledge of an experience will lead to claims of knowing rather than remembering.

Since deciding if a recollection is something remembered or something known is a source monitoring decision, this points to an additional concern: The difficulty in reliably discriminating true from false memories. The distribution of true and false memories in terms of sensory details will overlap -- some true memories will be vague, some false memories will use true sensory information in the construction of the recollection, and some false memories will have been rehearsed and elaborated. Nonetheless, in general true memories should contain more sensory details than false memories since they are derived from real experiences. Johnson and her colleagues (1988) found that memories contained more sensory information than imagined experiences and Hyman et al. (1998) found that remembered events contained more than known events. Thus many researchers have been able to find an overall difference between true and false memories in several ratings (Hyman \& Pentland, 1996), in remember/know judgments (Conway, Collins, Gathercole, \& Anderson, 1996), and in the content of the verbal descriptions (Pezdek, et al., 1997).

However, the overall difference masks two important questions: first, can recovered true memories be discriminated from false memories, and second, can false memories that have been repetitively elaborated be discriminated from true memories. Hyman and Pentland (1996) had individuals who recovered true memories and created false childhood memories over the course of the three interviews. When they asked individuals to rate all their memories, they found that the true memories that they could recall throughout the sessions were the most clearly and confidently remembered. They also found that recovered true memories (events not recalled in the first session and later remembered) and false memories were both rated lower than the always 
remembered true memories. In addition, recovered true memories and created false memories were not reliably different from one another. Hence, there may be no way to discern recovered from false memories. To our knowledge, no one has looked at how false memories that are held for an extended time compare to true memories. We suspect that as sensory information is added to false memories, they will become more difficult to discern from true memories.

\section{False Memories, False Self}

People create false memories. Sometimes the errors will be small: adding someone to a party who wasn't actually there, thinking one's role was larger than it actually was (Ross \& Sicoly, 1979), remembering the pain as more severe than it was (Ross, 1989), or downplaying personal foibles and inflating one's value (Greenwald, 1980). Sometimes the errors will be larger-forgetting events that were previously important for self-definition (Hirst, 1994; Usita, Hyman, \& Herman, 1998), creating an entire event in one's childhood (e.g., Hyman et al., 1995), or creating an adult experience (Kassin, 1997; Kassin \& Kiechel, 1996). Since the self is constructed from memories, the self will be a false self, based on beliefs and memories that do not accurately represent the past.

Although many of these changes may simply serve the goal of preserving a confident ego (Greenwald, 1980), others may be more damaging. If a person comes to believe that he or she was abused as a child, this is a change that may have negative effects on the ego. This change could alter anyone's self conception -- even individuals who experienced a less than ideal childhood may find child abuse a qualitative change in their understanding of their past. This is clear when considering the narratives of individuals who recover memories of abuse (e.g., Bass \& Davis, 1988; Pendergrast, 1995). The abuse becomes a part of how these people define themselves, something they must integrate with their life stories. In Jane Smiley's fictional case of 
Ginny, the new memory changed her life to the point where she indicated life as she knew it ended and a new life began. These changes may be difficult to reconcile with previous self conceptions for some individuals but may provide a narrative that accounts for many previously unexplained instances in one's life.

The memories that include abuse will not only affect self-definition, but will also affect an individual's interactions with others. If the accused perpetrator is a member of the family or a family friend, the memories will likely cause schisms in the relationships. The memories may force a person to re-evaluate the types of social interactions she or he has with others.

These changes in self-concept and relationships with others are justified when the recovered memories are of events that actually happened. In contrast, if the individual has created false memories, then the changes are a catastrophic error. The individual develops a false sense of self based on events that never occurred. The individual interrupts relationships with important individuals for a false cause.

This is the argument that has been played out in many families and in court cases across the country for the last several years. Individuals recover memories of abuse. They rewrite their personal narrative and change their relationships based on the memories. Families often contend that the memories are false-that they are the result of suggestions and social pressure. Families argue that they have been wrongfully cut off from children, siblings, and grandchildren. In the absence of some evidence external to memory, it is difficult, if not impossible, to know which narrative corresponds to historical truth.

Although these cases are dramatic, they exist because they are instances of how human memory functions. The inability to differentiate between false memories and historically accurate memories raises the question of how to balance historical and narrative truth (Spence, 1982). If a 
person believes that a memory is accurate, how is society to deal with this? Are we to accept that person's belief and focus on promoting health and welfare? Or are we to question that belief and take an investigative role? These questions are relevant for most memories discussed in therapy and not just memories of child abuse. Although we need to be concerned with distinguishing false and historically accurate memories, we must not lose sight of the practical implications of individuals dealing with what they believe is their past.

Memory is always constructed. What we remember will be constructed from residual information and from general schematic knowledge structures. In addition, memory construction often takes place within a social context and in response to social pressures. Thus the memories we construct reflect the suggestions and stories told by others. Many of our childhood memories may actually be stories that we heard others, such as parents or siblings, tell. We imagine the stories, and perhaps eventually adopt the image and story as our own memory. Much of the past is constructed in a social environment. This may explain how individuals fail to remember abuse or come to mislabel abuse -- they have adopted the story of the perpetrator (see Hyman \& Kleinknecht, in press). As Hyman and Pentland (1996) suggested, life is an ongoing misinformation experiment, where the outcome is that the self is memory's illusion.

The fact that memory is constructed also means that history is constructed. Consider the ongoing spin doctoring in the political arena. The need to write a favorable interpretation of the present and the past to argue for a certain political viewpoint has inspired numerous versions of political events. Consider the current effort to write the generally accepted version of President Clinton's affair with Monica Lewinsky. Did the President lie? Did he give honest, but not particularly revealing answers? Is independent prosecutor Starr an honest public servant striving to uncover serious crimes? Is he instead a man with a political agenda out to discredit a President 
with whom he disagrees? Although all of us alive now will have lived through these episodes, the eventual story we develop will be dependent on which narrative we adopt. History is written by the victors, or perhaps the victors are those who write a version of history that becomes the accepted version. In essence, we are living the nightmare of George Orwell's (1949) 1984. We may not be experiencing the negative totalitarian state described, but we certainly are experiencing the constant historical and personal revisions.

Nonetheless, there must be some limit on how malleable memory is. If memory was constantly being altered by the whims of our most recent interactions, then surely these changes would be problematic. We should experience difficulties accurately tracking the world, and conversations would be constant miscommunication in which people would have difficulties identifying experiences they shared. Hyman (in press) argued that the malleability of memory is an evolved trait that must balance opposing pressures. On one side are pressures favoring memory malleability -- pressures like updating memory to continue to recognize constancy in the face of small changes and pressures to change memory to better fit with social groups. On the other side are pressures for memory accuracy -- pressure to be able to learn from the past and be able to recognize shared experiences. The outcome of these pressures appears to be a memory system that is generally reliable. The gist will generally be accurate, as will most remembered details. Nonetheless, the system needs to be integrative. This means that schematic intrusions will occur. In addition, the memory system serves social interaction, and thus response to social pressure will also be observed. Therefore, extreme errors are possible, although most likely infrequent. Conversely, there should be times when memory is highly accurate. Thus the self as defined by autobiographical memory will be generally resilient, providing us with some confidence in who we are and who we can become. 


\section{References}

Barclay, C. R., \& DeCooke, P. A. (1988). Ordinary everyday memories: Some of the things of which selves are made. In U. Neisser \& E. Winograd (Eds.), Remembering reconsidered: Ecological and traditional approaches to the study of memory (pp. 91-125). Cambridge: Cambridge University Press.

Bartlett, F. C. (193.2). Remembering: A study in experimental and social psychology. Cambridge: Cambridge University Press.

Bass, E., \& Davis, L. (1988). The courage to heal: A guide for women survivors of child sexual abuse. New York: Harper \& Row.

Beins, B. C. (1993). Using the Barnum Effect to teach about ethics and deception in research. Teaching of Psychology, 20, 33-35.

Belli, R. F. (1989). Influences of misleading postevent information: Misinformation interference and acceptance. Journal of Experimental Psychology: General, 118, 72-85.

Ceci, S. J., Huffman, M. L. C., Smith, E., \& Loftus, E. F. (1994). Repeatedly thinking about non-events. Consciousness and Cognition, $\underline{3}, 388-407$.

Ceci, S. J., Loftus, E. F., Leichtman, M. D., \& Bruck, M. (1994). The possible role of source misattributions in the creation of false beliefs among preschoolers. International Journal of Clinical and Experimental Hypnosis, $\underline{42}$, 304-320.

Conway, M. A., \& Dewhurst, S. A. (1995). The self and recollective experience. Applied Cognitive Psychology, 9, 1-19.

Conway, M. A., Collins, A. F., Gathercole, S. E., \& Anderson, S. J. (1996). Recollections of true and false autobiographical memories. Journal of Experimental Psychology: General, $\underline{25}, 69-95$. 
Eysenck, H. J., \& Eysenck, S. B. G. (1968) Eysenck personality inventory. San Diego, CA: Educational and Industrial Testing Service.

Forer, B. R. (1949). The fallacy of personal validation: A classroom demonstration of gullibility. Journal of Abnormal and Social Psychology, 44, 118-123.

Garry, M., Manning, C. G., Loftus, E. F., \& Sherman, S. J. (1996). Imagination inflation: Imaging a childhood event inflates confidence that it occurred. Psychonomic Bulletin \& Review, 3, 208-214.

Glick, P., Gottesman, D., \& Jolton, J. (1989). The fault is not in the stars: Susceptibility of skeptics and believers in astrology to the Barnum Effect. Personality and Social Psychology Bulletin, 15, 572-583.

Goodyear, R. K. (1990) Research on the effects of test interpretation: A review. The Counseling Psychologist, 18, 241-257.

Goff, L. M., \& Roediger, H. L., III (1998). Imagination inflation for action events: Repeated imaginings lead to illusory recognition. Memory \& Cognition, 26, 20-33.

Greenwald, A. G. (1980). The totalitarian ego: Fabrication and revision of personal history.

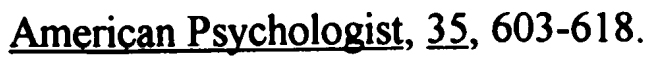

Hirst, W. (1994). The remembered self in amnesiacs. In U. Neisser \& R. Fivush (Eds.), The remembering self: Construction and accuracy in the self-narrative (pp. 252-277). NY: Cambridge University Press.

Hyman, I. E., Jr. (in press). Creating false autobiographical memories: Why people believe their memory errors. To appear in E. Winograd, R. Fivush, \& W. Hirst (Eds.), Ecological approaches to cognition: Essays in honor of Ulric Neisser. Hillsdale, NJ: Erlbaum. 
Hyman, I. E. Jr., \& Billings, F. J (1998). Individual differences and the creation of false childhood memories. Memory, 6, 1-20.

Hyman, I. E., Jr., Chesley, C. A., \& Thoelke, R. S. (1997, November). False Memories: False Personality Feedback Affects Plausibility Judgments. Paper presented at the meeting of the Psychonomic Society. Philadelphia, PA.

Hyman, I. E. Jr., Gilstrap L. L., Decker, K. L., \& Wilkinson, C. L. (1998). Manipulating remember versus know judgments in autobiographical memories. Applied Cognitive Psychology, 12, 371-386.

Hyman, I. E. Jr., Husband, T. H., \& Billings, F. J. (1995). False memories of childhood experiences. Applied Cognitive Psychology, 9, 181-197.

Hyman, I. E. Jr., \& Kleinknecht, E. E. (in press). False childhood memories: Research, theory, and applications. In L. M. Williams, \& V. L. Banyard (Eds.), Trauma and memory. Sage. Hyman, I. E., Jr., \& Neisser, U. (1992). The role of the self in recollections of a seminar. Journal of Narrative and Life History, 2, 81-103.

Hyman, I. E. Jr., \& Pentland, J. (1996) The role of mental imagery in the creation of false childhood memories. Journal of Memory and Language, 35, 101-117.

Hyman, I. E., Jr., \& Rubin, D. C. (1990). Memorabeatlia: A naturalistic study of long-term. Memory \& Cognition, 18, 205-214.

James, W. (1890). Principles of Psychology. NY: Holt

Johnson, M. K., Foley, M. A., Suengas, A. G., \& Raye, C. L. (1988). Phenomenal characteristics of memories for perceived and imagined autobiographical events. Journal of Experimental Psychology: General, 117, 371-376. 
Johnson, M. K., Hashtroudi, S., \& Lindsay, D. S. (1993). Source monitoring. Psychological Bulletin, 114, 3-28.

Kassin, S. M. (1997). The psychology of confession evidence. American Psychologist, 52, 221 233.

Kassin, S. M., \& Kiechel, K. L. (1996). The social psychology of false confessions: Compliance, internalization, and confabulation. Psychological Science, 7, 125-128.

Kelley, C., Amodio, D., \& Lindsay, D. S. (1996, July). The effects of 'diagnosis' and memory work on memories of handedness shaping. Paper presented at the International Conference on Memory, Padua, Italy.

Lindsay, D. S. (1990). Misleading suggestions can impair eyewitnesses' ability to remember event details. Journal of Experimental Psychology: Learning, Memory, and Cognition, $16,1077-1083$.

Lindsay, D. S. (1997). Increasing sesitivity. In D. Read \& S. Lindsay (Eds.), Recollections of trauma: Scientific research and clinical practice (pp. 1-16). New York: Plenum.

Lindsay, D. S., \& Read, J. D. (1994). Psychotherapy and memories of childhood sexual abuse: A cognitive perspective. Applied Cognitive Psychology, $\underline{8}, 281-338$.

Loftus, E. F. (1979). Eyewitness testimony. Cambridge, MA: Harvard University Press. Loftus, E. F. (1993). The reality of repressed memories. American Psychologist, 6, 93-107. Loftus, E. F. (1997). Dispatch from the (un)civial memory wars. In D. Read \& S. Lindsay (Eds.), Recollections of trauma: Scientific research and clinical practice (pp. 171-194). New York: Plenum.

Loftus, E. F., Donders, K., Hoffman, H. G., \& Schooler, J. W. (1989). Creating new memories that are quickly accessed and confidently held. Memory \& Cognition, 17, 607-616. 
Loftus, E. F., \& Pickrell, J. E. (1995). The formation of false memories. Psychiatric Annals, 25, 720-725.

McCloskey, M., \& Zaragoza, M. (1985). Misleading postevent information and memory for events: Arguments and evidence against memory impairment hypothesis. Journal of Experimental Psychology: General, 114, 3-18.

Neisser, U. (1982): John Dean's memory: A case study. In U. Neisser (Ed.), Memory observed: Remembering in natural contexts (pp. 139-159). San Francisco: Freeman and Company.

Neisser, U. (1988). Five kinds of self-knowledge. Philosophical Psychology, 1, 35-59.

Orwell, G. (1949). 1984. NY: Harcourt Brace Jovanovich, Inc.

Pendergrast, M. (1995). Victims of memory: Incest accusations and shattered lives. Hinesburg, Vermont: Upper Access, Inc.

Pezdek, K., Finger, K., \& Hodge, D. (1997). Planting false childhood memories: The role of event plausibility. Psychological Science, 8, 437-441.

Roediger, H. L. III, \& McDermott, K. B. (1995). Creating false memories: Remembering words not presented in lists. Journal of Experimental Psychology: Learning. Memory and Cognition, 21, 803-814.

Rotter, J. B. (1966). Generalized expectancies for internal versus external control of reinforcement. Psychological Monographs, 91 (1, Whole No. 609).

Ross, M. (1989). The relation of implicit theories to the construction of personal histories. Psychological Review, 96, 341-357.

Ross, M., \& Sicoly, F. (1979). Egocentric biases in availability and attribution. Journal of Personality and Social Psychology, 37, 322-336. 
Schooler, J. W., Bendiksen, M., \& Ambadar, Z. (1997). Taking the middle line: Can we accommodate both fabricated and recovered memories of sexual abuse? In M. Conway (Ed.), False and recovered memories (pp. 251-292). Oxford: Oxford University Press.

Smiley, J. (1991) A Thousand Acres. NY: Knopf.

Spanos, N. P., Cross, P. A., Dickson, K., \& DuBreuil, S. C. (1993). Close encounters: An examination of UFO experiences. Journal of Abnormal Psychology, 102, 624-632.

Tulving, E. (1985). Memory and consciousness. Canadian Psychology, 26, 1-11.

Spence, D. P. (1982). Narrative truth and historical truth: Meaning and interpretation in psychoanalysis. New York: Norton.

Usita, P. M., Hyman, I. E., Jr., \& Herman, K. C. (1998). Narrative intentions: Listening to life stories in Alzheimer's Disease. Journal of Aging Studies, 12, 185-197.

Wilkinson, C., \& Hyman, I. E., Jr. (in press). Individual differences related to two types of memory errors: Word lists may not generalize to autobiographical memory. Applied Cognitive Psychology.

Williams, L. M. (1995). Recovered memories of abuse in women with documented child sexual victimization histories. Journal of Traumatic Stress, 8, 649-673.

Zaragoza, M. S., \& Lane, S. M. (1994). Source misattributions and the suggestibility of eyewitness memory. Journal of Experimental Psychology: Learning, Memory, \& Cognition, 20, 934-945.

Zaragoza, M. S., \& Mitchell, K. J. (1996). Repeated exposure to suggestion and the creation of false memories. Psychological Science, 7, 294-300. 
False Memory, False Self -- 35

\section{Figure Caption}

Figure 1. Plausibility Ratings based on Profile Acceptance and Feedback that Events were and were not Related to the Personality Profile. 


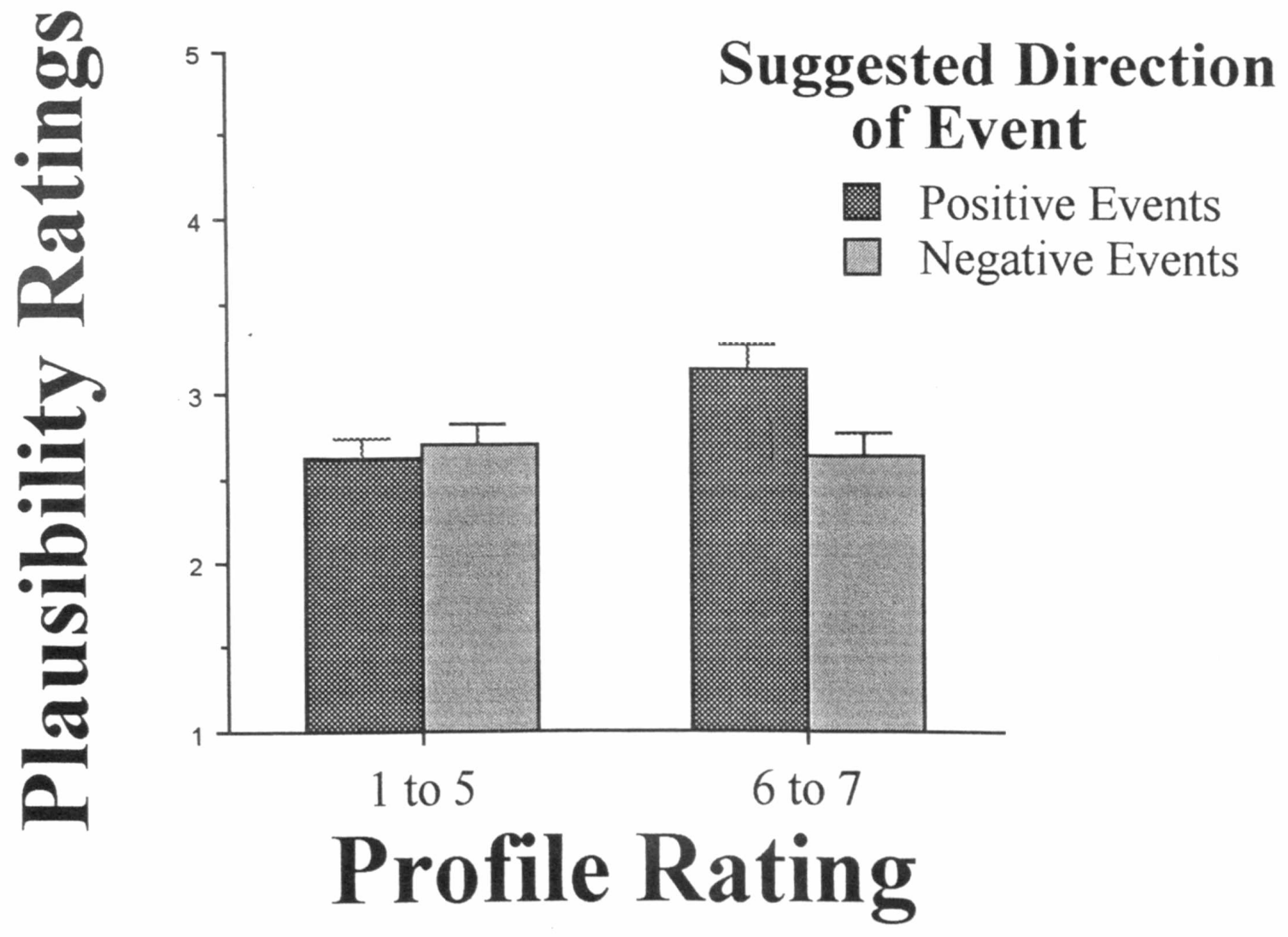

